\title{
14 Sense of place and socio-cultural values in fishing communities along the English Channel
}

\author{
Timothy G. Acott and Julie Urquhart \\ School of Science, University of Greenwich, Chatham Maritime, UK
}

\begin{abstract}
There is increasing interest in the social and cultural impacts of marine fisheries in coastal communities. This chapter uses the idea of 'sense of place' to explore the material and perceptual relations that emerge as a result of marine fishing in a range of villages and towns in France and England along the English Channel. Currently sense of place is an underused concept in resource management in general and within fisheries management in particular. We show how sense of place can be used to make visible a range of social and cultural values that emerge from the process of marine fishing. These values can then be expressed within a cultural ecosystem services framework, potentially helping to make the results accessible to a broader range of stakeholders, including policy makers and those involved in developing sustainable communities. The chapter concludes with some thoughts about the usefulness of approaches like actor network theory in providing relational perspectives for understanding marine fisheries management.
\end{abstract}

\subsection{Introduction}

Coastal communities exist on the littoral boundary between land and sea, with the influence of the marine environment and its living resources spilling out onto the land in a range of heterogeneous associations. Marine fishing is often thought of as a primary industry providing a valuable source of food and jobs for those involved in the sector. However, marine fisheries also interface a largely hidden undersea world and a series of ecologic-socio-cultural-economic translations that help drive the creation of a particular sense of place in coastal towns that is often linked to fishing. Fishing activity is bound up in relational processes, with the act of catching fish taking place at sea, but resulting in the creation of networks of influence and activity on land, including fish landing, selling and processing through to the creation of particular individual and community identities linked to a fishing way of life. The process of fishing, therefore, creates a range of values that tie people, places and ecosystems into a network of relational encounters.

This chapter explores the importance of fisheries as a generator of social and cultural values for coastal communities by reference to a sense of place study in 
fishing towns and villages along the English Channel in England and France carried out as part of the Channel Integrated Approach for Marine Resource Management (CHARM) III Interreg IVa project. In fisheries management, the idea of community has often not been given a high priority in policy development (Jentoft 2000). However, if a sustainable future for marine fishing is to be realised, people and communities should form a central element of policy making. New perspectives and methods are needed that make visible the wide range of cultural and social values that are generated by marine fishing to stakeholders involved in policy making. In other areas of resource use there are attempts to raise the profile of the community concept as central to building more sustainable places (Marsden and Hines 2008). We suggest that sense of place is a useful approach to begin to understand the range of social and cultural values emerging from the relational process that connects marine fishing and terrestrial communities and is important in planning for a sustainable future.

Sustainability, however, is a notoriously difficult term to pin down, with many definitions and typologies that describe its meaning (Williams and Millington 2004). Agyeman and Evans (2004) define it as follows: "the need to ensure a better quality of life for all, now and into the future, in a just and equitable manner, whilst living within the limits of supporting ecosystems" (pg. 157). This definition begins with the idea of quality of life and then casts that in terms of ecosystem limits (Blay-Palmer 2011). This has particular relevance for fisheries where approaches to management have tended to exclude explicit reference to well-being and focus on understanding ecosystems through the application of rational / science-centric paradigms to manage fish stocks and their resulting economic value.

This chapter explores how marine ecology, through the process of marine fishing, drives a series of terrestrial relationships that are woven into material and phenomenological worlds. Using sense of place as an approach, we explore how fishing practice is enrolled into community relationships and discuss how emergent cultural values contribute to developing a narrative about sustainable communities. Drawing on ideas of cultural ecosystem services (MEA 2005; Mace and Bateman 2011) we show how sense of place can be used as an approach to identify a range of cultural values that are generated by marine fishing. This has applied implications for fisheries management by making visible relations that might otherwise be hidden in studies that focus on ecological and economic dimensions of fisheries management. The chapter begins by reviewing literature describing the importance of social and cultural research to marine fisheries management and examining the idea of sense of place and the importance of this concept for understanding fishing communities. A case example is then presented that details research into sense of place and fishing and demonstrates the utility in unpacking some of the natural, social and cultural values of marine fishing. The conclusion draws together the findings of the case example and describes the future research potential of bringing together ideas of sense of place and cultural ecosystem services for sustainable marine fisheries management. The use of non-dualistic conceptual theories to help understand relational processes resulting from marine fishing is commented on. 


\subsection{Social and cultural aspects of fisheries: the role of sense of place}

It is well documented that policy makers have been slow to include social and cultural dimensions as part of the development of fisheries policy (Symes and Phillipson 2009). This is despite increasing evidence of the importance of developing holistic approaches to fisheries management (Firn Crichton Roberts Ltd 2000; Forst 2009) alongside understanding the importance of people's ethical values and perceptions (Jacquet 2009). In policy there is increasing recognition of the need to better understand the social, cultural and economic impacts of fishing (as, for example, in the recent proposals for the reform of the European Common Fisheries Policy (CFP), the European Integrated Maritime Strategy and the European approach to Integrated Coastal Zone Management). In the UK increasing interest in the social impacts of fisheries is evidenced by the recent Defra (Department for Environment, Food and Rural Affairs) project entitled Sustainable Access to Inshore Fisheries (SAIF) that examined the social impacts of England's inshore fisheries alongside economic and environmental impacts. A gap analysis on behalf of Defra identified the need for enhanced research effort to understand community and social cohesion in inshore fisheries (eftec 2010).

In Europe, the CFP is a major initiative that has influenced marine fishing since its inception; however, there are serious concerns as to its efficacy. Despite reform in 2002, the measures adopted yielded poor results and many fish stocks remain outside or almost outside safe biological limits with issues concerning poor enforcement of the CFP regulations, discarding, illegal landings, mesh sizes too small to protect juvenile fish and misallocation of catches (see, for example, EC 2009). A further major review of the CFP was announced in 2008 to be finalised by the end of 2012. Although there is recognition that such policy reviews need to be aware of the social relevance of the regulations they implement, there is little evidence-based research to inform the decision-making process. As Symes and Phillipson (2009) argue, policy makers seem to be largely unaware of the social context and relationships that make up fishing communities and the authors go as far as asserting that EU fisheries policy is largely to blame for many of the problems faced by fishing communities, as it tends to favour the more economically efficient operation of the large-scale sector.

The literature on social and cultural impacts of fishing is dispersed in a range of academic publications (Urquhart, Acott et al. 2011). Studies consider the lack of incorporation of social objectives into fisheries policy (Steelman and Wallace 2001; Symes 2005; Symes and Phillipson 2009) or focus on social impact assessments (Bradshaw, Wood et al. 2001; Pollnac, Abbott-Jamieson et al. 2006; McClanahan, Castilla et al. 2009). Processes of social representation and organisa- 
tion of inshore fishing have been captured in more anthropological studies (NadelKlein and Davis 1988; Nadel-Klein 2000; Symes and Frangoudes 2001; Williams 2008) where an important element is the emphasis on fishing as not just an occupation or a means of earning a living (Nuttall 2000; Jacob, Farmer et al. 2001; Brookfield, Gray et al. 2005). One challenge for fisheries management is how to capture the range of tangible and intangible cultural values that are associated with marine fishing. The idea of sense of place provides some methodological and conceptual possibilities in this area.

Understanding cultural values such as identity, heritage, attachment and social cohesion is not an easy task. It can be complex to try and unravel the relationships that people form with places; making them relevant in a policy-making context is perhaps even harder. However, sense of place is an approach that can help provide perspectives on community relationships and how people identify with a place. One of the potential benefits of sense of place is that it draws upon a range of academic disciplines including psychology, human geography, sociology and anthropology to understand complex human-environment relationships and, within the field of social science and human geography, there is an extensive literature on how places are socially constructed, the role of place in identity and how people become attached to place (Relph 1976; Tuan 1977; Proshansky, Fabian et al. 1983; Altman and Low 1992; Massey and Jess 1995; Holloway and Hubbard 2001; Creswell 2004).

Drawing on phenomenological perspectives, humanistic geographers, such as Tuan (1974) and Relph (1976), suggest that place attachment or sense of place relies on the individual and the emotional meanings people associate with a place and is based on the social relationships and processes that occur in a particular setting. Thus, sense of place entails complex human-environment relationships and, as Kaltenborn (1998) contends, it is bound up with the meanings attributed to places interpreted and constructed by people. In his seminal work Relph (1976, p. 6-7) is particularly concerned with "exploring the various ways in which places manifest themselves in our experience or consciousness of the lived world." However, Malpas (2008) states that there is a common tendency to view culture as something that is additional to and separate from its materiality. As well as human experience and perception, places are defined by the physical environment (Relph 1976; Tuan 1977). Indeed, place attachment is related to the bonds that people form with their environment (Hummon 1992; Low and Altman 1992; Stedman 2003), with a number of scholars suggesting that physical attributes contribute to place satisfaction (Shumaker and Taylor 1983; Stedman 2003). Eisenhauer et al. (2000) assert that there is a reciprocal relationship between physical environments and people in what Crist (2004, p.12) calls a "cultivation of receptivity" in which humans can receive meaning from the world through "opening oneself, listening, watching, being within, letting be, or merging into." In this sense, social life and culture will influence place meanings, but the biophysical elements of place are also important.

Stedman (2003) argues that places are co-constructed, drawing on the socially constructed meanings of humans, but also being influenced by the material reality of the biophysical world. He suggests that symbolic and value aspects of place are 
partially based on some form of material reality. This tension between the material and the subjective leads Malpas (2008, p. 204) to suggest that "culture and heritage are always configured in relation to the 'material', and that there can be no clear or sharp distinction between the natural and the non-natural, the tangible and the intangible." Thus, to understand the cultural values that emerge from marine fisheries there needs to be consideration of the inherent interconnectedness of both material and subjective dimensions. This simple insight into the relational importance of the material and the subjective begins to open up new possibilities for imagining how marine fishing exerts influence in terrestrial locations and how sense of place might be used to capture those relationships.

Although there is perhaps a tendency in popular media not to differentiate between different types of fishing (e.g. inshore / offshore), fisheries activity can give rise to a diversity of relational associations and place characters; for instance large industrial ports to small coves with just a few boats. Sense of place can provide a conceptual framework for understanding this diversity and how people form attachments to and identify with different environmental settings. These relations give rise to a range of material and non-material values associated with fisheries. There is clearly increasing interest in understanding the social and cultural dimensions of fisheries but it is rare to find the idea of sense of place explicitly used even though the idea is often implied. For instance, in the run up to the reform of the CFP, EU Fisheries Commissioner Maria Damanaki stated in a meeting with artisanal and small-scale fishers that “... small-scale fisheries are very important for the survival of coastal communities, for their identity, culture, history and way of life" (ICSF 2010). There seems to be an implicit reference to the idea of sense of place in this comment even though the concept is not directly addressed. Sense of place can be used to explore the elements that Commissioner Damanaki mentions alongside other place-based issues like attachment, identity, dependence and belonging. An important aspect of sense of place is trying to understand how people value their environment, and identifying elements of the environment that are important to them (Schofield and Szymanski 2011).

While fisheries-related studies have not explicitly used sense of place there are calls for the concept to have a larger role in other areas of natural resource management. Williams and Stewart (1998) contend that sense of place allows resource managers to identify and respond to the emotional and spiritual bonds people form with localities. They suggest that sense of place is a way of integrating people into the idea of ecosystem management. Indeed, sense of place is now appearing in areas relating to ecosystem assessment. Church et al. (2011) suggest that a distinctive sense of place can contribute to a range of human value needs. However, sense of place can also help to draw out some of the cultural services provided by ecosystems, for instance, cultural identity, heritage values, spiritual services, inspiration, aesthetic appreciation, recreation and tourism.

The following section presents a case example of marine fishing along the English Channel to illustrate how the concept of sense of place can be a useful approach for unpacking some of the material/subjective social and cultural values of marine fishing. Some background to fishing activity and communities in the Channel is presented first; this is followed by an exploration of how sense of place 
can be used to reveal some of the tapestry of social and cultural relations that emerge as a result of fishing activity.

\subsection{Fishing communities along the English Channel}

The English Channel separates southern England from northern France and joins the North Atlantic Ocean to the west and the North Sea to the east. It is approximately $560 \mathrm{~km}$ long and varies in width from $240 \mathrm{~km}$ at its widest, to $34 \mathrm{~km}$ in the Strait of Dover. The Channel covers an area of around $75,000 \mathrm{~km}^{2}$ and is the world's busiest international seaway, used by over 500 commercial vessels per day (BMT 2009). As part of an Interreg IVa project CHARM III, a study was conducted on the sense of place of fishing communities along the English Channel in southern England and northern France (Acott and Urquhart 2012) (Fig. 14.1). Places were identified to ensure a broad range of sites in terms of the size of port, location, diversity of industries, extent and type of fishing activity and tourism (Box 1).

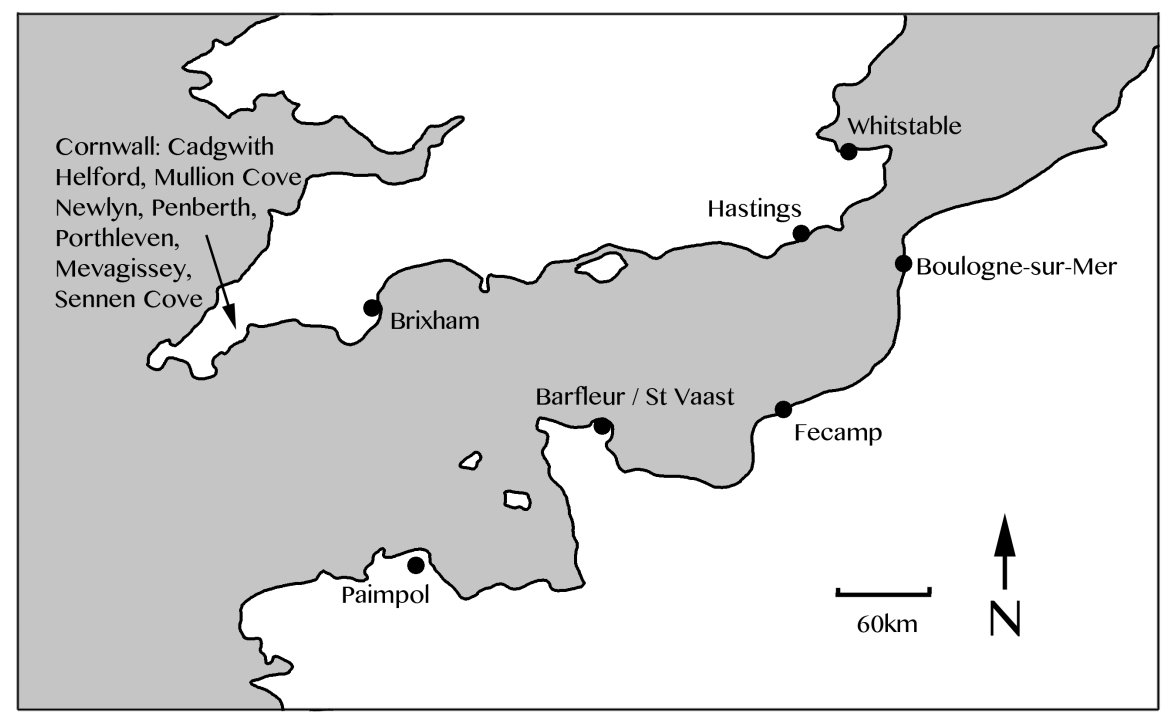

Fig. 14.1 Sense of place study sites. 


\section{Box 1: Case study sites}

Case study sites in England were Whitstable (Kent), Hastings (East Sussex), Brixham (Devon) and a range of sites in Cornwall. Whitstable is a seaside town and port in northeast Kent well-known for its oysters, which have been collected here since at least Roman times. Hastings is a town and borough on the coast of East Sussex and is one of Britain's oldest fishing ports, with boats working from the shingle beach in front of the Old Town for over 1000 years and it was one of the medieval Cinque Ports. Brixham is a small fishing town in Devon, in the south west of England. Fishing and tourism are its main industries and it has been an important fishing port for centuries and it was the largest fishing port in the south-west in the Middle Ages. Cornwall is one of the UK's most important regions for marine fishing, with fishing places ranging from the busy fishing port of Newlyn, with around 150 fishing vessels working out of the harbour, to small fishing coves such as Penberth, with a handful of small open day boats pulled up on the shore.

In France, the case study sites were Boulogne-sur-mer (Nord-pas-deCalais), Fecamp (Upper Normandy), Barfleur \& Saint Vaast (Lower Normandy) and Paimpol (Brittany). Boulogne-sur-mer is a city in the north of France in the Nord-pas-de-Calais region and is the most important fishing port in France, with over 7,000 people earning a living in the fisheries sector (in the catch sector and processing). Over 380,000 tonnes of fish are processed annually in the port's fish processing district Capécure, making it Europe's largest fish processing centre. Only around $10 \%$ of the fish is landed in Boulogne is from local boats, the remainder is transported by road from other ports in France and the UK. Fecamp is a town in the Seine-Maritime department in the Haute-Normandie. Fishing has been important in Fecamp for centuries, with salt-herrings dating from the 10th century and smoked herrings from the 13th century. Its recent history centres around the Newfoundland cod fishing throughout the 19th century and up to the 1970s. After the collapse of the cod fishery, only a small inshore fleet remains and pleasure boats dominate the harbour. Barfleur is a small harbour town in the Basse-Normandie region of France, located $25 \mathrm{~km}$ east of Cherbourg on the eastern coast of the Cotenin peninsula. It is home to a small fishing fleet and is an important site for the harvesting of Barfleur Mussels and oysters, although 700 years ago it was the largest fishing port in Normandy. Saint-Vaast-la-Hougue is located about 7 miles south of Barfleur in the Basse-Normandie region of France. Saint-Vaast has extensive oyster beds, where oysters are cultivated for consumption and renowned for their high quality. Paimpol is a harbour town in the Côtesd'Armor department in Brittany and is a popular tourist destination and hosts a bi-annual Sea Shanty festival. The town was important for the Icelandic and Newfoundland cod fishing. Although this extensive fleet has now gone, a small fishing fleet still exists in Paimpol, and there are also oyster beds. 


\subsection{Sense of place as conceptual framework}

To date fisheries-related studies have not explicitly made sustained use of the idea of sense of place. The present study demonstrates the potential of sense of place to provide a conceptual approach for understanding the complex multidimensional human-environment relationships of marine fishing by considering place as an outcome of tangled material / subjective relations. These relations give rise to a range of values associated with fisheries including heritage values, spiritual values, identity values etc. However, for sense of place to be a genuinely useful approach for policy makers and practitioners there needs to be a broader consideration of the epistemological foundation within which such studies are presented. In the UK, and more broadly, there is increasing interest in understanding the value of ecosystem services (Garcia 2003; MEA 2005; NEA 2011) an important element of which asks how does the natural environment contribute to cultural value.

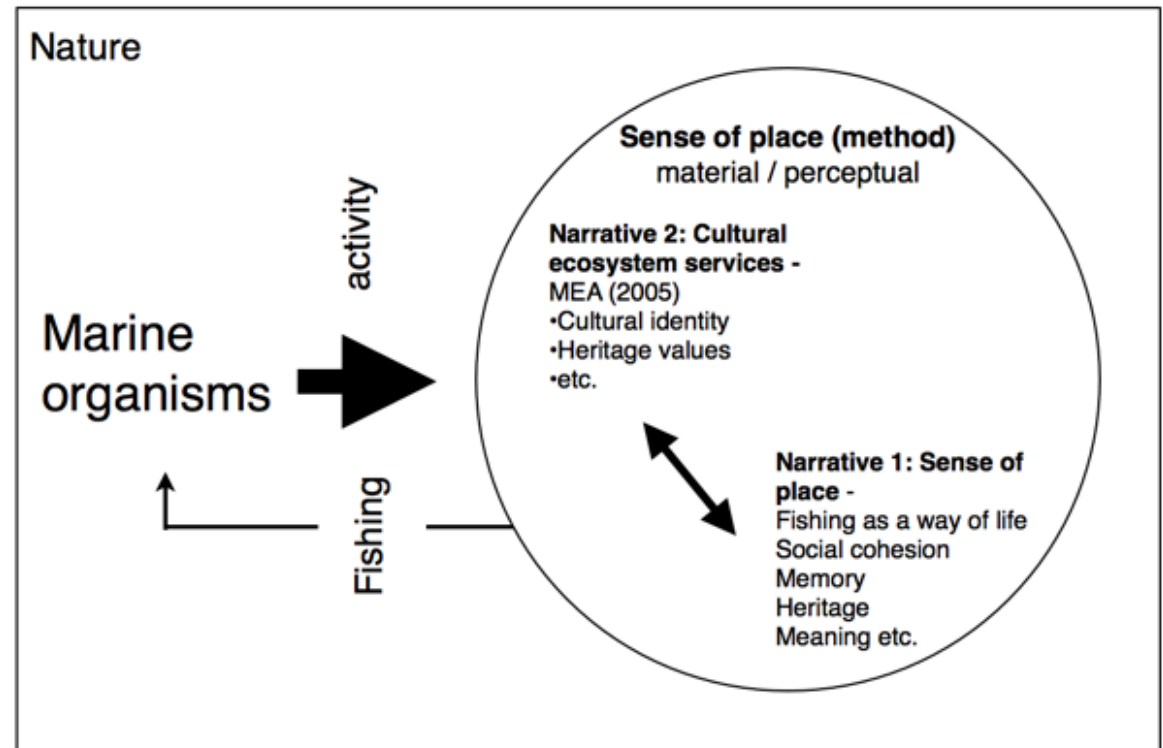

Fig. 14.2 Sense of place conceptual framework.

The relationship between marine organisms, fishing activity, sense of place (method) and emerging narratives is depicted in Fig. 14.2. Fishing activity is a driver that translates marine organisms into a range of socio-cultural effects. Sense of place was used as an approach in our study to view the material / perceptual dimension of fishing activity and resulted in a range of outcomes being identified. We used sense of place as a methodological approach, but also expressed the re- 
sults within a narrative framework consistent with this tradition (Fig. 14.2: narrative 1). In addition to fishing activity being a driver of socio-cultural outcomes, there is a feedback loop from those outcomes back to the marine organisms and the fishing activity. If the range of effects spilling out from the fishing activity are not recognised (or valued) that has the potential to modify the fishing effort that will in turn impact on marine ecology.

A multi-method approach was adopted to explore sense of place in the case study sites (see Acott \& Urquhart 2012) including a desk study of tourism representation and fishing, scoping visits, photographic surveys of material culture, townscape assessments and a total of 112 semi-structured interviews conducted with a range of stakeholders including fishermen, representatives of fishing communities, fishermen's organisations, heritage providers (e.g. museum curators), tourism providers (e.g. hotel/restaurant owners, tourism office), and artists and galleries. Participants were recruited by identifying the key stakeholders in each case study site through a web-based search, along with snowballing (Babbie 2010), where participants recommended other potential participants.

\subsection{Place identity and character}

Marine fishing can exert a powerful force in shaping the material environment of terrestrial communities and the identity of people that live in and around fishing places. The extent of the impact depends on a range of factors including size of the community, range of other activities in a location, type of fishing operation, and the nature of the physical environment. Large populations centres have the ability to dilute the influence of fishing in ways that a small village does not. Similarly, if there is a range of other activities (e.g. tourist attractions, industrial centres, leisure facilities etc.) in an area, for instance Boulogne-sur-mer (France), fishing becomes just one dimension that contributes to place character. However, in a small coastal village such as Cadgwith in Cornwall (England), fishing is the dominant activity and forms the heart and soul of the community. In a range of locations fishing plays an important but different role in the creation of a place. In many cases the central focus of the town is the harbour and fishing is deeply embedded in the character of the place. A participant from a small fishing community, Mevagissey commented:

"The whole place still revolves around the fishing industry really ... If you think Mevagissey you think working fishing harbour" (Christine ${ }^{1}$, fishing community representative, Mevagissey)

\footnotetext{
ity.

${ }^{1}$ The names of participants have been changed throughout to preserve anonym-
} 
While another from a larger fishing port, Brixham, explained:

"It's Brixham, isn't it, the fishing industry is Brixham so, you know, it is just part and parcel of the town" (Simon, tourism provider, Brixham)

The material dimension of sense of place includes not just the marine ecosystem and the coastal landscape but also those objects and buildings created by people. In fishing communities, the physical objects associated with fishing contribute to place identity and are markers of identity. These material objects may include fishing boats (Fig. 14.3), nets, pots, street decoration, buildings etc. and the selective (re)production of these material objects can strongly influence the physical character of place. Such objects constitute an important element of the materiality upon which ideas of sense of place can be constructed and interpreted from an aesthetic perspective. As an example, there was overwhelming agreement that harbours look better with fishing boats, rather than other vessels, such as yachts. Participants felt that fishing boats, especially the smaller inshore boats, have a certain charm that contributes to the character of a harbour, perhaps reflecting a sense of authenticity and contemporary working activity.



Fig. 14.3. Beach launched boats on the Stade at Hastings

Another important element shaping the physical character of fishing places is the abundance of fishing gear (nets, floats, storage boxes etc.). In some places the 
fishing gear is stored in racks or crates in order to keep it tidy. In other places gears are laid out on quaysides or beaches. Arguably the presence of fishing gear adds authenticity in that contemporary activities of fisherman are contributing and adding to the environment.

"They [tourists] love seeing pots and nets on the quayside" (Leon, artist, Barfleur)

"It's like crab pots, every photograph of any Cornish fishing village there's a crab pot in the middle of it" (Victor, fisherman, Sennen Cove)

\subsection{Authenticity and fishing heritage}

There were concerns about the authenticity of fishing heritage, with fears of fishing harbours becoming like theme parks if the fishing stopped, with fishermen paid to mend their nets on the harbour-side, wearing sou'westers and talking to tourists about the days when they used to fish. Although it might be possible to recreate the idea of fishing in a staged inauthentic way, this would create a different sense of place to that being created as part of a contemporary working industry. Part of the cultural value created by marine fishing is its active and dynamic contribution to place character.

"I mean economically Saint Vaast and Barfleur it's really, I mean fishing it really contributes to them and without fishing or without oyster farming it wouldn't be the same, it wouldn't be Saint Vaast anymore" (Nicole, heritage provider, Saint-Vaast)

"Without the fishing there is no character in Hastings... It's just part of the landscape here, it's part of what Hastings, it's part of it's cultural identity" (Bob, Fisherman, Hastings)

"And there is an attitude here, in Whitstable, we like the mess. We like the noise. We like the activity, because you can come through here in the middle of winter, on a cold, wet, rainy day, and there will be activity here. There will be people around, life, activity, people going about their day to day jobs" (Adam, harbour master, Whitstable)

In addition to sense of place being able to help construct a picture of contemporary environments, there is also a temporal dimension that is expressed through the idea of heritage. Heritage is part of the narrative in understanding sustainable community development and is important for quality of life and providing a sense of belonging that is central to issues of cultural identity (Tweed and Sutherland 2007). Vileniske (2008) suggests that built heritage plays a role in the creation of local identity, cultural diversity and social cohesion. In addition to providing part 
of the fabric of the built environment, heritage can also contribute to human needs in providing symbolic meanings. A theme emerged concerning heritage and the importance of fishing as both a past and contemporary activity. Fishing in the past is memorialised in the landscape through the buildings (net huts, fish cellars, warehouses etc.) and infrastructure (e.g. capstan wheels) that remain today (Fig. 14.4). In addition to these tangible elements of heritage there are intangible aspects, including traditions, stories, skills, culture and memories.

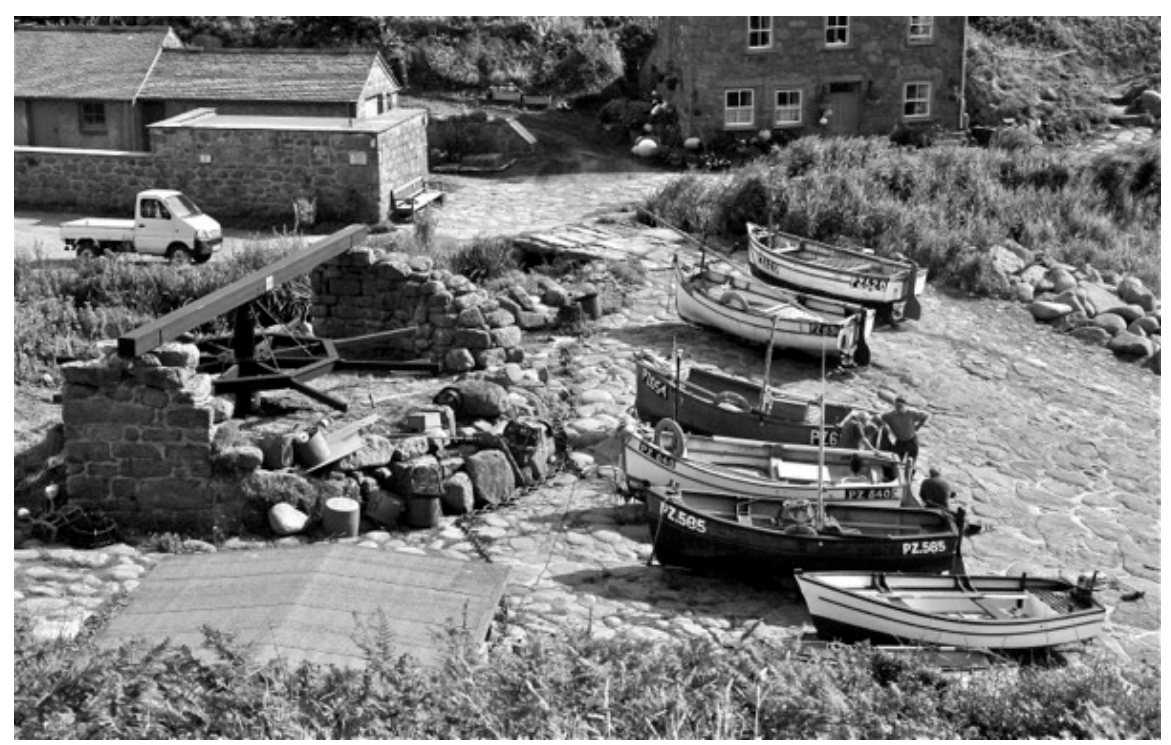

Fig. 14.4. Preserved capstan wheel and contemporary fishing boats in Penberth, Cornwall.

Most of the respondents felt it important to preserve this long history and cultural heritage of fishing:

"I think we are interested in activities which form part of who we are and whether it's fishing or whether it's another activity it's, you know, how does that activity define who people are and from that point if you think that yes it is important to preserve the cultural history of an activity, in that case I would say well yes because fishing is part of, it's all part of that" (Aimée, heritage provider, Fécamp)

"Fishing is part of the heritage of Boulogne, it's definitely a part of the heritage of the town" (Pierre, tourism provider, Boulogne)

Having a strong link to the past can help root a community in its locale and give it a sense of identity and strength to adapt to a changing world. There is a connection to the past through the skills that have been passed down through generations, skills that cannot be learnt in a textbook, such as how to get the boats up 
and down the beach, how to mend nets (Fig. 14.5) and how to prepare the fish. Boats, gear, knowledge and skills have been passed on from father to son for generations and there is often a sense of pride in coming from a local fishing family.



Fig. 14.5. Mending nets in Barfleur

Thus, the past often plays an important role in the construction of collective identities as it can help make sense of and confront future challenges (Dalby and Mackenzie 1997). This is demonstrated by one participant:

"It roots you in something, whether you choose to reject it or embrace it, if you know where you come from perhaps it gives you more confidence to go on. Perhaps you've got more of a chance to make choices if you know where you come from" (Gemma, borough council representative, Hastings)

The way the past is remembered is subject to interpretation and representation. This might be through the way material objects are displayed and interpreted in a museum, interpretation boards on the quay, stories that have been passed down or through the memories of those who were engaged in fishing or fish-related activities. A number of participants spoke about how it is important not to romanticise past fishing activity, but that it was often a difficult and dangerous way of life. The relationship between the heritage of fishing and contemporary practice was important. It was the time-deepened tradition of fishing that provided a cultural rootedness, but this was tied into, and not separate from, the contemporary continuation of fishing. In some of the small fishing places, like Cadgwith, there was a 
clear concern that if the fishing disappeared the heart would be taken from the community. An understanding of heritage is central to a dialogue on sustainable communities and is closely bound up with the creation of distinctive place characters.

\subsection{Art, fishing and a sense of place}

The character of a place is subject to many influences, one of which is the objectification of marine fishing through the activities of artists. As Tuan (1976, p. 267) comments: "In artworks people's experiences of life and the world are vividly objectified." The coast has long been a source of inspiration and an attraction for artists, due to the particular light and environment.

"I like that moment, that sort of in-between moment, of the tide, the fluctuations between the high tide and low tide and the whole kind of lights and how the light changes, and at the same time, how the daily life of fishermen changes as well" (Philippe, Artist, Paimpol)

The activity of fishing, fishermen and fishing boats often appear in paintings and influence other artworks. As a creative resource, marine fishing is incorporated into the material environment through the actions of sculptors, artists and writers. Artistic activity is carried out for numerous reasons, including the revenue created by a lucrative tourism market. People are attracted to iconic images as representations of places visited. However, relationships between art and marine fishing are more complex than a single economic dimension might infer. In addition to the 'creation' of artworks, the 'process' of painting or sculpture is related to the negotiation of livelihood opportunities and personal reflection.

In one village an art gallery was providing a source of income for a family where the fisherman had retired from fishing due to ill health. The gallery exhibited a wide range of 'art' products, many associated with marine fishing. A series of paintings, created by the fisherman, reflected his recollections of what happened to him over the years while fishing. Another member of the family had learned to sculpt and was now making models of fishing boats that were for sale in the shop. The gallery was the locus of relationships that tied together fish, fishing, inspiration, reflection, skills (painting and sculpture), family relationships and income. The physical presence of the gallery combined with the production and selling of artworks formed a web of relationships, not just for the family involved but also for visitors and potential customers to the area.

Perhaps one of the most well-known and extensive records of fishing in art is the Newlyn School of Painters, a colony of artists that lived and painted in and around southwest Cornwall in the late eighteenth and early nineteenth centuries. 
Many of the artists had spent time painting the pastoral lives of people in Brittany in France, and found a similar source of inspiration in Cornwall in the fishing communities. They saw a way of life that seemed untouched by the Industrial Revolution and wanted to capture that on canvas before it disappeared.

\subsection{Personal and community identity}

In addition to exploring the influence of marine fishing on place character, a sense of place approach allowed feelings of personal and community identity to be expressed by participants. Being a fisherman gave fishers and fishing families a rootedness in their community and in the place and provided a 'marker' of identity. For these reasons, fishing is more than a means of earning a living and van Ginkel (2001) suggests that fishermen may strive to continue fishing even when it is no longer economically viable to do so, as it defines their identity as individuals, households and communities. For example, one inshore fisherman from Cadgwith spoke of his love for fishing and the way of life it offered:

"You've got to want to do the job, it's not a job you do for the money, you wouldn't do it in all honesty. You've got to love the job, want to do the job and then the money's secondary you know. That's the way I see it. ... fishing is a way of life, a completely different way of life" (Craig, fisherman, Cadgwith)

Fishers' attachments to fishing also revolved around the harbour or beach as a physical setting where the fishing activity took place. Harvey (1996) suggests that places are often seen as the 'locus of collective memory' where group identity is created through the construction of group memories. Harbours and beaches were important in the construction of both individual and collective identities. Working in a particular environment and use of that space created a sense of belonging to that environment. For fishing communities, as in other rural areas, fishing is part of a cultural process that is collectively constructed and defined. The role of fishing in community life and social cohesion was seen as important by most of the participants, not just the fishermen. This was illustrated by one participant, who came from a fishing family:

"I mean we got a good community here and we've got a nice school, lots and lots of different things going on in the village. And I think the fishing industry plays a huge important, well, keeping it all going" (Christine, fishing community, Mevagissey) 
These findings support Brookfield et al. (2005, p. 56) who assert that: "the fishing industry is seen to be the forum through which community bonds, values, knowledge, language and traditions are established, confirmed and passed on ... For fisheries-dependent communities, fishing is the glue that holds the community together."

Another reported impact on social structure was the perception of an increase in outsiders moving into communities. Sometimes incomers were seen as diluting community cohesion, and changing the nature of community structure. Incomers and local residents may have different attachments to place, as illustrated by one fisherman from Cornwall. He indicated the potential for conflict between incomers and locals, with each forming different attachments:

"We've been fighting for 14 years to try and get a new quay there so we don't have to put our fish in mud before it goes into the car to bring it over. But all the residents, most of the residents because there are very few permanent residents don't want any development. So which is really hypocritical in a way because they, a lot of those people have bought houses in the village because it's a picturesque fishing village, they don't want any more fishing activity" (Phil, fisherman, Cornwall)

However, this response was balanced by other views that saw the importance of incomers, particularly linked to tourism, as vital for economic revenue.

Fishermen often referred to the physical environment, to the sea, the weather, tides and the coastal landscape. Their identities were co-constructed through a combination of knowledge and relationships to the sea/land-scape together with their individual perspectives, experiences and relationships within the community. The occupational identity of fishers was also mediated by their daily engagement with the natural environment. Although conversations were not necessarily framed around religion and spirituality there was clearly a connection being made with the sea that was deeply emotional and bonding:

"It's for the love of the work of the job and the love of the sea which is why, I mean you don't become a fisherman randomly just like that. There is the love of the sea and of the environment itself which is important which pushes to accept the difficulties of the profession which is actually quite, it is hard work being a fisherman ... Well the freedom, the pleasure of fishing, of trying to understand nature - there is quite a few things that, there is quite a few factors which bring you to loving what you do to the kind of work and to the profession and that bring you to practising it" (Théodore, fishermen's organisation, Boulogne) 


\subsection{Cultural ecosystem services}

The earlier sections have provided a brief description of the emergent themes relating to sense of place. In discussions with stakeholders and policy makers it is clear there are conceptual difficulties in communicating qualitative sense of place ideas, in particular to those more familiar with an epistemological position emerging from positivism and the harder natural and physical sciences.

For studies to have impact and applied meaning beyond life in academic books and journals, thought must be given to the salience of the results for other stakeholders and the broader policy-making community. Currently there is increasing importance being given to the idea of ecosystem services (Fletcher, Saunders et al. 2011; Lundy and Wade 2011; Chan, Satterfield et al. 2012; Mace, Norris et al. 2012; Robertson 2012) and the ecosystem approach to fisheries (Garcia 2003). However, the valuation of cultural ecosystem services is a particularly difficult area as identified in the UK National Ecosystem Assessment (Church, Burgess et al. 2011, p. 63): "One important challenge is how to develop a conceptual and/or methodological approach which allows the humanities and more interpretive social science disciplines to make their distinctive contributions to the assessment in such a way as to strengthen the integration of scientific, economic, cultural and socio-political evidence for policy." This perspective is echoed by Chan et al. (2012) who suggest that methods from diverse social sciences should be used to help characterise cultural services. In this regard, sense of place may offer a conceptual and methodological approach to investigate socio-cultural values associated with marine fishing.

Aligning sense of place with cultural ecosystem services has the potential to provide a policy-relevant context within which the contribution of marine fisheries to sustainable community development can be articulated. Therefore, drawing on the framework provided by the MEA (2005), we interpreted our results in the context of cultural ecosystem services (Table 14.1; see also Fig. 14.2: narrative 2). As Table 14.1 illustrates, many of the sense of place themes identified in our study can be understood as cultural ecosystem services.

Table 14.1. Sense of place and cultural ecosystem services of marine fisheries

\begin{tabular}{ll}
\hline Sense of Place themes & Cultural Ecosystem Services \\
\hline Fishing as 'a way of life'. & Cultural identity \\
Contribution of fishing to social cohesion and commu- & \\
nity identity. & \\
Fishing as 'iconic' marker of identity. &
\end{tabular}


Fishing is represented through 'memories' in the land- Heritage values scape: harbours, capstan houses, net huts etc.

Memory of past fishing activity influences identity.

Fishers feel a deep connection to the sea through their Spiritual services daily engagement with it.

\section{Fishing and the marine environment provide inspiration Inspiration} for artists, music and literature.

Fishing influences place character through its material Aesthetic appreciation presence (contemporary and historic), e.g. boats, fishing gear, buildings, street decoration etc.

'Fishing culture' contributes to the appeal of places for Recreation \& tourism tourism through the presence of fishing fleets, heritage and fish as cuisine.

Tourist boat trips, buying fresh fish etc.

However, some caution does need to be taken in pursuing this goal. Chapter 16 of the UK National Ecosystem Assessment is a discussion of cultural ecosystem services (Church, Burgess et al. 2011). This primarily deals with the way particular 'environmental settings' can provide ecosystem services. Through the lens of sense of place, we have revealed how an environmental setting is a result of a complex entanglement of nature and society where marine fishing is acting as a process of identity creation that connects the often unseen undersea world with places on land. This might be through direct experience of the fishermen, or indirectly through the way fishing activities spill out into coastal locations (place character, community identity, personal identity).

There are two important conceptual points to note about using sense of place and ecosystem services in this way. First, sense of place is understood with reference to relational associations of activities (fishing and non-fishing), events and 'things' that connect the undersea world with terrestrial places. The focus is, therefore, to understand place-making as processes that span different environmental settings of the sea and land. In using sense of place as a lens to understand these processes, we are exploring sets of relationships being created and in part driven 
by marine fishing. Part of the marine ecosystem service is a direct experience of fishing and being at sea, but further complications emerge as the idea of fishing gets incorporated into the socio-cultural mix of different places. Mechanisms should be found to incorporate this process-driven, relational understanding into fisheries policy, coastal zone management and sustainable community development more broadly. It is possible that the popular categories of supporting, provisioning, regulating and cultural services might prove conceptually limiting and new approaches to thinking about relationships between the material / subjective worlds might be needed. Possible conceptual frameworks for building this approach include actor network theory (Latour 2005), hybrid geography (Whatmore 2002) and non-representational theory (Thrift 2007). Actor network theory (ANT), as an example of a non-dualistic approach, offers the potential to explore processes and relations that are driven by the activity of marine fishing. ANT is coconstructionist and can be used to identify "how relations and entities come into being together" (Murdoch 2001, p. 111). In addition to conceptual ideas like ANT there is a broad area of research examining the inter-connection of social and ecological components within marine systems (Perry and Rosemary 2010). A special issue of Marine Policy (vol. 37, 2013) reports on approaches to help bridge the social ecological divide while developing perspectives on governance strategies.

Second, we adopted a narrative approach where the voices of the participants were allowed to emerge and tell the story of the importance of marine fishing in their lives and the places in which they live. While economic valuation in ecosystem services is fundamentally important, the relationships between land and sea, human and ecosystem, need to be understood through narrative as well as economic valuation. In order to plan for a sustainable future for fishing communities, there needs to be broader understanding of the multiple cultural ecosystem values that result and spill out from the act of fishing. The economic value of fishing, and associated activities, is ultimately only one type of value in a broader network of relationships that emerge where the activity of fishing occurs. These values are depicted in Table 1 as relating to various dimensions of identity, heritage, spirituality, inspiration, aesthetic and recreation. Chan et al. (2012, p. 16) call for a "new research community and program at the nexus of ecological-economic analysis and the social sciences of decision- making, a program dramatically different from the existing ES [ecosystems services] research program."

\subsection{Conclusion}

The focus of this chapter has been to generalise the contribution that marine fishing makes to sense of place across the different study locations. However, the qualitative research undertaken provides a rich source of data that describes material and subjective associations with marine fishing in particular localities. Alt- 
hough beyond the boundaries of this chapter there is considerable scope to mine the data to provide local contextual accounts of sense of place related to particular villages, towns or regions (for examples see Urquhart and Acott (2013) and Urquhart and Acott (in press)). The cultural ecosystem services identified during our research form part of the broader tapestry of issues important in sustainable community development. Tweed and Sutherland (2007) discuss cultural heritage for sustainable urban development while Roseland (2000) considers the broader necessity of integrating environmental, economic and social objectives into sustainable community development. This theme is taken further by Britto (2011) who suggests a multi-modal systems method for capturing the broad dimensionality associated with sustainable development. We believe that sense of place allied to a cultural ecosystems services perspective can produce a policy-relevant account of the importance of marine fishing. The challenge will then be to embed that perspective into local and regional planning frameworks so that the broader cultural contribution of marine fishing to sustainable community development can be evaluated.

Brookfield et al. (2005) contend that fishing is the glue that holds the community together. Perhaps rather than thinking about it as 'sticking' together preexisting entities, fishing can be considered as an activity that drives the process of place-making. Particular places emerge with fishing playing an integral part in the formation of place character and identity. If policy makers involved with fishing places are to plan for a sustainable future there needs to be a clear articulation and understanding of the myriad social, economic and environmental relationships that emerge as a result of marine fishing. Sense of place provides a starting point for exploring these relationships. Without such a perspective, social and cultural values can be overlooked or only partially addressed in the decision-making process. We argue that sense of place studies can deliver a policy-relevant account of cultural ecosystem values that emerge when marine and terrestrial environments are drawn together by the activity of fishing. Such analysis needs to be combined with ecological, environmental and economic valuations to understand how marine fishing can contribute to a sustainable future for inshore fishing communities.

\section{References}

Agyeman, J. and B. Evans (2004). "'Just sustainability': the emerging discourse of environmental justice in Britain?" The Geographical Journal 170(2): 155-164.

Altman, I. A. and S. M. Low, Eds. (1992). Place attachment. New York, Plenum.

Babbie, E. (2010). The Basics of Social Research. Belmont, CA, USA, Wadsworth Cengage Learning. 
Blay-Palmer, A. (2011). "Sustainable communities, an introduction." Local Environment 16(8): 747-752.

BMT (2009). Reducing Risk in the English Channel/La Manche Traffic Separation Schemes. final report for the Maritime and Coastguard Agency (MCA) and the Ministere de l'Ecologie, de l'Energie, du Developpement durable et de l'Amenagement du territoire, BMT Isis Ltd.

Bradshaw, M., L. Wood, et al. (2001). "Applying qualitative and quantitative research: A social impact assessment of a fishery." Applied Geography 21: 69 - 85.

Britto, C. M. (2011). "Sustainable Community Development: A Brief Introduction to the MultiModal Systems Method." Systemic Practice and Action Research 24(6): 533-544.

Brookfield, K., T. Gray, et al. (2005). "The concept of fisheries-dependent communities. A comparative analysis of four UK case studies: Shetland, Peterhead, North Shields and Lowestoft." Fisheries Research 72: 55-69.

Chan, K. M. A., T. Satterfield, et al. (2012). "Rethinking ecosystem services to better address and navigate cultural values." Ecological Economics 74: 8-18.

Church, A., J. Burgess, et al. (2011). Cultural Services. UK National Ecosystem Assessment: Technical Report. Cambridge, UNEP-WCMC.

Creswell, T. (2004). Place: a short introduction. Oxford, Blackwell Publishing.

Crist, E. (2004). "Against the Social Construction of Nature and Wilderness." Environmental Ethics 26: 5-24.

Dalby, S. and F. Mackenzie (1997). "Reconceptualising local community: environment, identity and threat." Area 29(2): 99-108.

EC (2009). Green Paper: Reform of the Common Fisheries Policy. Brussels, European Commission.

eftec (2010). Provision of Sustainable Access to Inshore Fisheries Research Gap Analysis. London, Defra.

Eisenhauer, B. W., R. S. Krannich, et al. (2000). "Attachments to Special Places on Public Lands: An Analysis of Activities, Reason for Attachments, and Community Connections." Society and Natural Resources 13(421-441).

Firn Crichton Roberts Ltd (2000). An assessment of the socio-economic costs \& benefits of integrated coastal zone management. G. S. o. E. S. U. o. Strathclyde), European Commission: 61.

Fletcher, S., J. Saunders, et al. (2011). "<A review of the ecosystem services provided by broadscale marine habitats.pdf>." Journal of Coastal Research 64(1): 378 - 383.

Forst, M. F. (2009). "The convergence of Integrated Coastal Zone Management and the ecosystems approach." Ocean \& Coastal Management 52(6): 294-306.

Garcia, S. M. Z., A.; Aliaume, C.; Do Chi, T.; Lasserre, G. (2003). The ecosystem approach to fisheries. Issues, terminology, principles, institutional

foundations, implementation and outlook. FAO Fisheries Technical Paper. Rome, FAO: 71.

Harvey, D. C. (1996). Justice, nature and the geography of difference. Cambridge, Blackwell.

Holloway, L. and P. Hubbard (2001). People and place: the extraordinary geographies of everyday life. Harlow, Pearson Education Ltd.

Hummon, D. M. (1992). Community attachment: Local sentiment and sense of place. Place attachment. I. Altman and S. M. Low. New York, Plenum Press.

ICSF (2010). ITQs a User Right, not a Property Right, confirms EU Commissioner for Fisheries and Maritime Affairs. I. C. i. S. o. Fishworkers.

Jacob, S., F. Farmer, et al. (2001). "Landing a definition of fishing dependent communities." Fisheries 26(10): 16-22.

Jacquet, J. (2009). "Silent water: a brief examination of the marine fisheries crises." Environment Development and Sustainability 11: 255-263.

Jentoft, S. (2000). "The community: a missing link of fisheries management." Marine Policy $\mathbf{2 4}$ 53-59.

Kaltenborn, B. P. (1998). "Effects of sense of place on responses to environmental impacts." Applied Geography 18(2): 169-189. 
Latour, B. (2005). Reassembling the social: an introduction to Actor-Network-Theory. Oxford, Oxford University Press.

Low, S. M. and I. I. Altman (1992). Place attachment: A conceptual inquiry. Place attachment. I. Altman and S. M. Low. New York, Plenum Press.

Lundy, L. and R. Wade (2011). "Integrating sciences to sustain urban ecosystem services." Progress in Physical Geography 35(5): 653-669.

Mace, G. M. and I. Bateman (2011). Conceptual framework and methodology. The UK National Ecosystem Assessment: Technical Report. Cambridge, UNEP-WCMC.

Mace, G. M., K. Norris, et al. (2012). "Biodiversity and ecosystem services: a multilayered relationship." Trends Ecol Evol 27(1): 19-26.

Malpas, J. (2008). "New Media, Cultural Heritage and the Sense of Place: Mapping the Conceptual Ground." International Journal of Heritage Studies 14(3): 197 - 209.

Marsden, T. and F. Hines (2008). Unpacking the quest for community: some conceptual parameters. Sustainable Communities: new spaces for planning, participation and engagement. T. Marsden. Oxford, Elsevier.

Massey, D. and P. Jess, Eds. (1995). A Place in the World? Oxford, Oxford University Press.

McClanahan, T. R., J. C. Castilla, et al. (2009). "Healing small-scale fisheries by facilitating complex socio-ecological systems." Rev Fish Biol Fisheries 19: 33-47.

MEA (2005). Ecosystems and Human Well-Being, Synthesis Report. Washington, D.C., Island Press.

MEA (2005). Millennium Ecosystem Assessment: Current State and Trends Assessment. Island Press, Washington D.C., Millennium Ecosystem Assessment.

Murdoch, J. (2001). "Ecologising Sociology: Actor-Network Theory, Co-construction and the Problem of Human Exemptionalism." Sociology 35(1): 111 - 133.

Nadel-Klein, J. (2000). "Granny baited the lines: perpetual crisis and the changing role of women in Scottish fishing communities." Women's Studies International Forum 23(3): 363-372.

Nadel-Klein, J. and D. L. Davis (1988). To Work and to Weep. St John's, Newfoundland, Institute of Social and Economic Research, Memorial University of Newfoundland.

NEA (2011). UK National Ecosystem Assessment: Understanding Nature's Value to Society. Synthesis of the Key Findings. Cambridge, UNEP-WCMC.

Nuttall, M. (2000). Crisis, risk and deskillment in North-east Scotland's fishing industry. Fisheries Dependent Regions. D. Symes. Oxford, Blackwell Science.

Perry, I. R. and O. E. Rosemary (2010). "Introduction: Coping with global change in marine social-ecological systems." Marine Policy 34(4): 739-741.

Pollnac, R. B., S. Abbott-Jamieson, et al. (2006). "Toward a Model for Fisheries Social Impact Assessment." Marine Fisheries Review 68(1-4): 1-18.

Proshansky, H. M., A. K. Fabian, et al. (1983). "Place-identity." Journal of Environmental Psychology (3): 57-83.

Relph, E. (1976). Place and placelessness. London, Pion.

Robertson, M. (2012). "Measurement and alienation: making a world of ecosystem services." Transactions of the Institute of British Geographers 37: 386 - 401.

Roseland, M. (2000). "Sustainable community development: integrating environmental, economic, and social objectives." Progress in Planning 54: 73-132.

Schofield, J. and R. Szymanski (2011). Sense of place in a changing world. Local heritiage, global context: Cultural perspectives on sense of place. J. Schofield and R. Szymanski. Farnham, Ashgate.

Shumaker, S. A. and R. B. Taylor (1983). Toward a clarification of people-place relationships: A model of attachment to place. Environmental psychology: Directions and perspectives. N. R. Feimer and E. S. Geller. New York, Praeger: 219-251.

Stedman, R. C. (2003). "Is it really just a social construction?: The contribution of the physical environment to sense of place." Society and Natural Resources 16(8): 671-685.

Steelman, T. A. and R. L. Wallace (2001). "Propety rights and property wrongs: Why context matters in fisheries management." Policy Sciences 34: 357-379. 
Symes, D. (2005). "Altering course: future directions for Europe's fisheries policy." Fisheries Research 71(3): 259-265.

Symes, D. and K. Frangoudes (2001). The Social Organisation and Reproduction of Inshore Fishing. Inshore Fisheries Management. D. Symes and J. Phillipson. Dordrecht, Kluwer.

Symes, D. and J. Phillipson (2009). "Whatever became of social objectives in fisheries policy?" Fisheries Research 95(1): 1-5.

Thrift, N. (2007). Non-representational theory: Space, politics, affect. Oxon, Routledge.

Tuan, Y.-F. (1974). Topophilia: A Study of Environmental Perceptions, Attitudes and Values. Prentice Hall.

Tuan, Y.-F. (1977). Space and place: The perspectives of experiance. Minneapolis University of Minnesota Press.

Tweed, C. and M. Sutherland (2007). "Built cultural heritage and sustainable urban development." Landscape and Urban Planning 83(1): 62-69.

Urquhart, J. and T. Acott (2013). "Constructing 'The Stade': Fishers' and non-fishers' identity and place attachment in Hastings, south-east England." Marine Policy(37): 45-54.

Urquhart, J. and T. Acott (in press). "A sense of place in cultural ecosystem services: The case of Cornish fishing communities." Society and Natural Resources.

Urquhart, J., T. Acott, et al. (2011). "Setting an agenda for social science research in fisheries policy in Northern Europe." Fisheries Research 108: 240-247.

van Ginkel, R. (2001). Inshore fishermen: cultural dimensions of a maritime occupation. Inshore Fisheries Management. D. Symes and J. Phillipson. Dordrecht, Kluwer.

Vileniske, I. G. (2008). "Influence of Built Heritage on Sustainable Development of Landscape." Landscape Research 33(4): 425-437.

Whatmore, S. (2002). Hybrid Geographies: Natures, Cultures and Spaces. London, Routledge.

Williams, C. C. and A. C. Millington (2004). "The diverse and contested meanings of sustainable development." The Geographical Journal 170(2): 99-104.

Williams, D. R. and S. I. Stewart (1998). "Sense of place: An elusive concept that is finding a home in ecosystem management." Journal of Forestry(96): 18-23.

Williams, R. (2008). Changing Constructions of Identity: Fisher Households and Industry Restructuring. PhD, Newcastle University.

actor network theory, 279, 301

Aesthetic appreciation, 300

Art, 296

attachment, 286, 287, 302, 303, 304, 305

authenticity, 292, 293

CHARM, 284, 288

co-constructed, 286, 298

co-constructionist, 301

collective memory, 297

Common Fisheries Policy, 285, 303

cultural diversity, 293

cultural ecosystem services, 279, 284, $299,300,302,305$

ecosystem services, 284, 290, 299, $300,301,303,304$

ecosystems, 279, 284, 287, 301, 302, 303
England, 279, 284, 285, 288, 291, 305

English Channel, 279, 284, 287, 288, 303

fisheries-dependent communities, 298, 303

France, 279, 284, 288, 291, 297

heritage, 286, 287, 290, 291, 293, 294, $295,300,301,302,305$

hybrid geography, 301

identity, 286, 287, 290, 291, 292, 293,

$294,297,298,299,300,301,302$,

$303,304,305$

inshore fishing, 286, 302

Integrated Coastal Zone Management, 285, 303

Integrated Maritime Strategy, 285

Newlyn School of Painters, 296

non-dualistic, 284, 301 
non-representational theory, 301

place meanings, 286

place satisfaction, 286

place-making, 300, 302

rootedness, 295, 297

semi-structured interviews, 291

Sense of place, 279, 284, 285, 286,

287, 288, 290, 291, 292, 293, 296,
297, 299, 300, 301, 302, 303, 304,

305

social cohesion, $285,286,293,297$, 299

social objectives, 285, 302, 304, 305

Sustainability, 284, 303

UK National Ecosystem Assessment, 299, 300, 303, 304

well-being, 284 